\title{
Painful Ejaculation - An Ignored Symptom
}

\author{
Muhammad Waqar $^{1}$, Kawa Omar $^{1}$, Amr Moubasher ${ }^{1}$, Oliver Brunckhorst ${ }^{2}$, Kamran Ahmed ${ }^{1}$ \\ 1. Urology, King's College Hospital NHS Foundation Trust, London, GBR 2. Urology, MRC Centre for Transplantation, \\ Guy's Hospital Campus, King's College London, King's Health Partners, London, GBR
}

Corresponding author: Muhammad Waqar, muhammad.waqar1@nhs.net

\begin{abstract}
The purpose of this review is to summarize the pathophysiology of ejaculation and look into prevalence, aetiology, diagnosis, and treatment of painful ejaculation. We carried out a comprehensive search of PubMed in order to look for literature on male painful ejaculation using keywords post-orgasmic pain, painful ejaculation, dysejaculation, odynorgasmia, post-orgasmic pain, or dysorgasmia.
\end{abstract}

Painful ejaculation has an alarming prevalence throughout the world, between 1 to $25 \%$. It has a detrimental effect on patients' quality of life as it reduces individual self-esteem and is associated with sexual dysfunction. Its aetiology includes simple infection or inflammation of the urinary tract, benign prostate hyperplasia, ejaculatory duct obstruction, post-radical prostatectomy and side effects of certain medications. Once reported, it should be investigations and treatments should be tailored according to the etiology. Both medical and surgical treatment is available depending on the cause of painful ejaculation.

Due to the sensitive nature of its presentation, it is a symptom that can be identified best when specifically asked. Our understanding regarding painful ejaculation is very limited and only a few articles have revealed insight into this topic. Further research is required in order to set proper guidelines for diagnosis and treatment of painful ejaculation.

Categories: Urology

Keywords: post-orgasmic pain, painful ejaculation, dysejaculation, odynorgasmia, post orgasmic pain, dysorgasmia

\section{Introduction And Background}

Orgasm-associated pain is defined as an agonising sensation occurring during orgasm. It has been mainly reported at the level of the penis, but pain at various sites including testes, rectum, or the lower abdomen had been reported [1]. It is also known as dysejaculation, odynorgasmia, dysorgasmia, or orgasmalgia [2]. This is a poorly understood phenomenon, therefore mostly ignored. The incidence of orgasm-associated pain has been reported from 1.9-25\% [3-4]. The duration of the pain can be a few seconds or persist up to two days [5-6]. The sensation can vary from a dull ache to unbearable pain [7]. Unfortunately, relatively few articles have shed light on this topic. The objective of this literature review is to find the incidence, causes, investigations, and potential management for painful ejaculation.

Review began 10/19/2020 Review ended 10/23/2020 Published 10/30/2020

๑) Copyright 2020

Waqar et al. This is an open access article distributed under the terms of the Creative Commons Attribution License CC-BY 4.0., which permits unrestricted use, distribution, and reproduction in any medium, provided the original author and source are credited.

\section{Review \\ Prevalence}

Painful ejaculation remains an under-reported symptom. A large-scale, multinational survey was carried out in the United States and six European countries in 2003, which looked into 12,815 male patients ranging from 50 to 80 years of age suffering from lower urinary tract symptoms (LUTS). Of these patients, $6.7 \%$ were suffering from painful ejaculation [8]. In another study, $25.9 \%$ of approximately 2000 sexually active men with LUTS, had been experiencing ejaculatory discomfort. In another two studies, the incidence was reported to be from 1.9 to $12 \%$ [3,9]. Thus, the prevalence ranges from 1.9 to $25 \%$ of men either as an isolated symptom or associated with other lower urinary tract symptoms. Moreover, a rise in the number of cases was noted with increased severity of LUTS assessed by international Prostate Symptom Score [4].

\section{Orgasm physiology}

Understanding the physiology of orgasm is crucial in comprehending painful ejaculation. In men, orgasm and ejaculation happen simultaneously. Ejaculation has two stages, emission and ejection [10]. Ejaculation and orgasm depend on a perplexing interplay between the central nervous system and the peripheral nervous system, with the inclusion of some neurotransmitters, namely dopamine, norepinephrine, serotonin, acetylcholine, and nitric oxide. Hormonal pathways also play a significant role in ejaculation. Typical hormones involved are oxytocin, prolactin, thyroid hormone, glucocorticoids, and sex hormones. Unfortunately, very few studies have evaluated hormones effect on ejaculation physiology [11-12]. Brain studies assessing ejaculation and orgasm have shown a significant role of the thalamus and hypothalamus in controlling sexual behavior [13,11]. In Figure 1 this connection has been demonstrated [1]. The sensory input from the dorsal nerve of the penis transmits sensation to the spinal cord. Stimulation of perineum and 


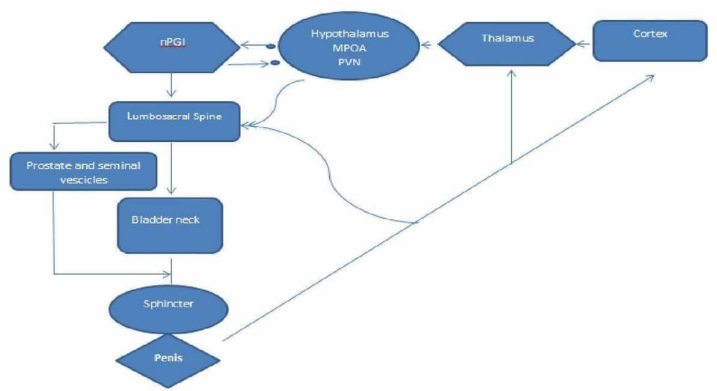

FIGURE 1: Physiology of orgasm and ejaculation.

MPOA: medical preoptic area, PVN: paraventrucular thalamic nucleus, nPGI: paragigantocellularis nucleus.

Emission and expulsion are the two phases of ejaculation. The initial step of the ejaculation procedure is the outflow stage, also called the emission phase. This starts by closure of the bladder neck preventing backflow of secretions. The epididymis, vas deferens, original vesicles, prostate organ, prostatic urethra, and bladder neck are all involved in this stage. This is followed by the ejection of prostatic secretion and spermatozoa from the vas deferens into the prostatic urethra. During the emission phase, both the pelvic and the hypogastric plexus play a vital role after receiving physical or visual stimulation [15]. This is continued by the ejection of semen through the urethral meatus. This is called the expulsion phase and is characterized by contractions of different striated muscle including bulbospongiosus and ischiocavernosus muscles [16]. Throughout the process, the bladder neck remains closed. The relaxation of the external urinary sphincter and activation of pudendal nerve fiber along with other accessory sexual organs are processed at the level of the brain, thus inducing the sensation of orgasm [12].

\section{Aetiology}

There are a multitude of factors implicated in painful ejaculation. Though few are life-threatening, painful ejaculation can significantly impact the individual's quality of life. Below we have listed the common possible causes.

Infectious or inflammation: Conditions such as orchitis, epididymitis, prostatitis, or urethritis have been found to cause painful ejaculation [17-18].

Benign prostate hyperplasia: Litwin study showed patients with benign prostate hyperplasia (BPH) were more prone to have painful ejaculation than the normal population [19].

Post radical prostatectomy: Intra-operative damage to the bladder neck and nerve fibre controlling bladder neck contraction and external sphincter muscle leads to orgasm related symptoms. In one study, it was shown that $9 \%$ of patients treated with radical prostatectomy suffered from painful ejaculation [12]. In another study, 33\% experienced painful ejaculation post-radical prostatectomy [20].

Seminal vesicle stone: The cause of seminal vesicle stones is still a mystery, but it is seen in patients with chronic infection, prostate cancer, reflux of urine, or diabetes mellitus. The majority of these patients present with painful ejaculation and hematospermia. Diagnosis is made by radiological assessment such as trans-rectal ultrasound and magnetic resonance imaging, MRI, or plain radiographs [21].

Zinner syndrome: It is a triad of ipsilateral renal agenesis, seminal vesicle cysts and ejaculatory duct obstruction. Seminal vesicle cysts are found in $70 \%$ of cases of ipsilateral renal agenesis. It is mostly an incidental finding but sometimes patients can present with painful ejaculation [22].

Ejaculatory duct obstruction (EDO): It is a rare condition that can be caused by several pathologies such as ejaculatory duct malformations, midline prostatic cysts, fibroses due to prostatitis or seminal vesiculitis, seminal vesicle (SV) stones, or scarring after endoscopic manipulation. EDO may present with painful ejaculation co-existing with infertility. This group of patients is difficult to manage due to their complex anatomy [23-25].

Chronic pelvic pain syndrome: Pudendal neuropathy has been mostly caused by nerve compression and can result in painful ejaculation [6]. Other areas of pain include the penile, scrotal, and peri-anal region. It is thought to be due to pelvic movements during intercourse. The damage mostly happens as the pudendal nerve passes between the sacrotuberous and sacrospinous ligaments [26]. Twenty-four percent of patients suffering from chronic pelvic pain syndrome (CPPS) were found to have ejaculatory pain regularly [27]. 


\section{Cureus}

Medication: Painful ejaculation is also seen with anti-depressant drugs. It was noticed with imipramine, desipramine, clomipramine, protriptyline, amoxapine, fluoxetine, and venlafaxine [28]. Muscle relaxants such as cyclobenzaprine was also reported to cause painful ejaculation [29]. Stopping these medications have shown improvement in patient symptoms.

Miscellaneous: Ejaculatory pain after vasectomy is rare but if it happens, it usually occurs at the scrotum [30]. Scarring of the vas deferens following inguinal hernia repair with mesh can also result in painful ejaculation [31]. It mainly results from migration of mesh resulting in permanent damage to nerve, vas deference, and spermatic cord.

Figure 2 summarizes the causes of painful ejaculation.

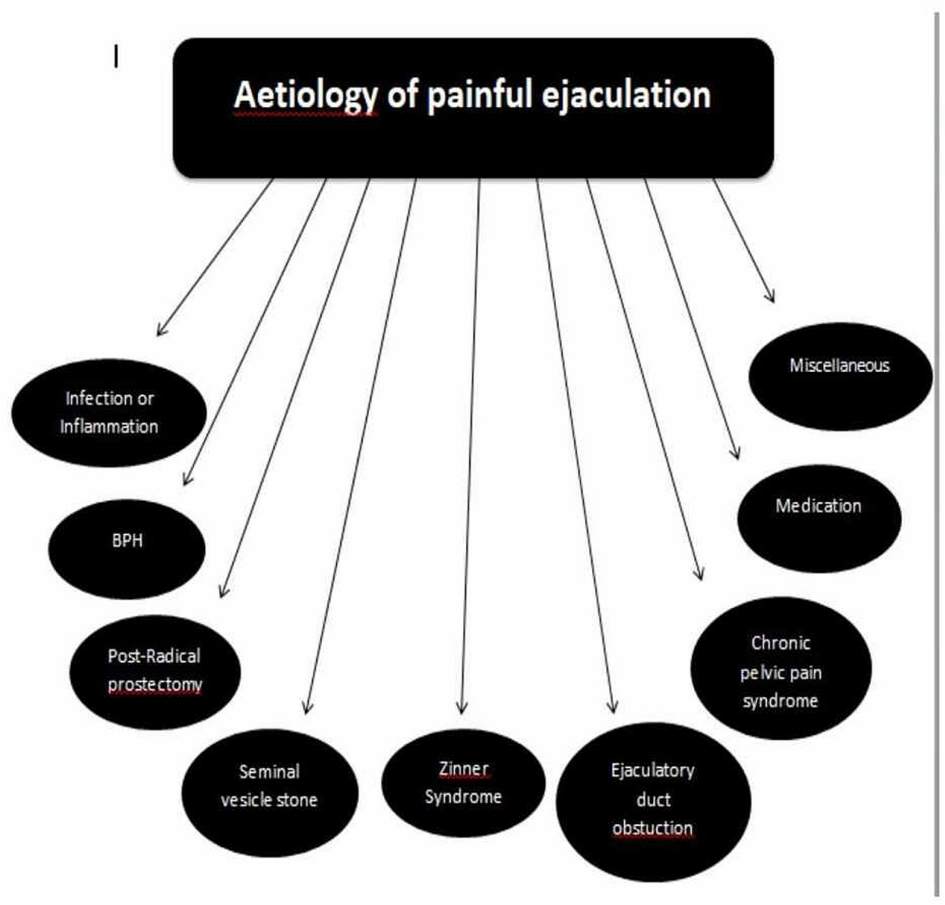

FIGURE 2: Aetiology of painful ejaculation

BPH: benign prostate hyperplasia

Investigations required are tailored to the suspecting cause of the painful ejaculation. Assessment of these patients includes a full history and physical examination including genitals and digital rectal examination for prostate. Investigation ranges from urinalysis, urine culture, and blood tests including PSA to transrectal ultrasound to check for ejaculatory duct obstruction or calculi. Cystoscopy can be performed if urethral stricture was suspected or urethrogram can be offered instead [3].

\section{Treatment}

Treatment depends upon the cause of post-orgasmic pain. If the cause is suspected to be infectious or inflammatory processes, antibiotics and non-steroidal anti-inflammatory drugs are used. For seminal vesicle related pain, transurethral seminal vesiculoscopy is the approach of choice [21]. In ejaculatory duct obstruction, transurethral resection of the ejaculatory duct or balloon dilatation can resolve the issue [32]. In one study, patients treated with tamsulosin for four weeks showed a significant improvement in symptoms [5]. This is also useful in post-radical prostatectomy related painful ejaculation [33]. In an article by Perez et al. [34], a young patient with post ejaculation pain was successfully treated with oral topiramate. Within a month, the patient's pain score improved from $8 / 10$ to $1 / 10$. Conventional analgesics and neuropathic pain therapies failed to eliminate ejaculatory pain. Painful ejaculation due to medication side effects can be controlled by stopping the medication. In the case of post inguinal hernia ejaculatory pain, exploration of wound and releasing the vas deferens from the scar tissue and dividing the ilioinguinal nerve proved to alleviate the pain [7]. Table 1 summarizes the treatment of painful ejaculation as per the aetiology. 


\section{Cureus}

\begin{tabular}{|l|l|}
\hline Condition/Aeitology & Treatment \\
\hline Infection (orchitis, epididymitis, prostatitis, or urethritis) & Antibiotic \\
\hline BPH & Tamsulosin \\
\hline Post radical prostatectomy & Tamsulosin \\
\hline Seminal vesicle stone & Transurethral seminal vesiculoscopy and removal of stone \\
\hline Anti-depressant drugs & Stop medication \\
\hline Ejaculation duct obstruction & Release vas deferens from scar and divide ilioinguinal nerve \\
\hline
\end{tabular}

TABLE 1: Treatment as per aeitology.

BPH: benign prostate hyperplasia

\section{Conclusions}

Painful ejaculation is an underreported symptom that has a detrimental effect on patients' quality of life and therefore should be actively identified by clinicians. It remains an often ignored symptom. It's a symptom that requires specific interrogation, with many patients often not volunteering their experiences at first. It has multiple causes and clinicians should specifically ask for it. Once reported, investigations and treatments should be tailored according to the etiology. Treatment varies from withdrawal of suspected agent (drugs) or prescribing right medical treatment (antibiotic, anti-inflammatory, or antibiotic). Surgical option is also available depending on etiology in form of resection of prostate, ejaculatory duct and neuolysis to correct pudendal neuropathy. Currently there are no specific guidelines on painful ejaculation by major urology bodies such as the American Urological Association (AUA), European Association of Urology (EAU), and NICE guidelines. This area that needs more research in order to have clear guidelines regarding its diagnosis and management.

\section{Additional Information}

\section{Disclosures}

Conflicts of interest: In compliance with the ICMJE uniform disclosure form, all authors declare the following: Payment/services info: All authors have declared that no financial support was received from any organization for the submitted work. Financial relationships: All authors have declared that they have no financial relationships at present or within the previous three years with any organizations that might have an interest in the submitted work. Other relationships: All authors have declared that there are no other relationships or activities that could appear to have influenced the submitted work.

\section{References}

1. Capogrosso P, Ventimiglia E, Cazzaniga W, Montorsi F, Salonia A: Orgasmic dysfunction after radical prostatectomy. World J Mens Health. 2017, 35:1. 10.5534/wjmh.2017.35.1.1

2. Parnham A, Serefoglu EC: Retrograde ejaculation, painful ejaculation and hematospermia . Transl Androl Urol. 2016, 592:601. 10.21037/tau.2016.06.05

3. Ilie CP, Mischianu DL, Pemberton RJ: Painful ejaculation. BJU Int. 2007, 99:1335-9.

4. Irwin D, Milsom I, Reilly K, Hunskaar S: Prevalence of lower urinary tract symptoms (Luts) in men: European results from the epic study. Eur Urol Suppl. 2006, 5:157.

5. Barnas J, Parker M, Guhring P, Mulhall JP: The utility of tamsulosin in the management of orgasmassociated pain: a pilot analysis. Eur Urol. 2005, 47:361-5.

6. Antolak SJ, Hough DM, Pawlina W, Spinner RJ: Anatomical basis of chronic pelvic pain syndrome: the ischial spine and pudendal nerve entrapment. Med Hypotheses. 2001, 59:349-53. 10.1016/s0306-9877(02)00218-9

7. Butler JD, Leach A, Hershman MJ, Histories C: Painful ejaculation after inguinal hernia repair heart failure with fludro- cortisone in Addison's disease. J R Soc Med. 1998, 91:1-2. 10.1177/014107689809100811

8. Rosen R, Altwein J, Boyle P: Lower urinary tract symptoms and male sexual dysfunction: the multinational survey of the aging male (MSAM-7). Eur Urol. 2003, 44:637-49. 10.1016/j.eururo.2003.08.015

9. Matsushita K, Tal R, Mulhall JP: The evolution of orgasmic pain (dysorgasmia) Following radical prostatectomy. J Sex Med. 2012, 9:1454-8. 10.1111/j.1743-6109.2012.02699.x

10. Kaplan HS: Hormones and sex. The New Sex Therapy, Active Treatment of Sexual Dysfunctions. Taylor \& Francis, New York; 1974. 1:46-61. 10.4324/9780203727317

11. Alwaal A, Breyer BN, Lue TF: Normal male sexual function: emphasis on orgasm and ejaculation . Fertil Steril. 2015, 104:1051-60. 10.1016/j.fertnstert.2015.08.033

12. Althof SE, McMahon CG: Contemporary management of disorders of male orgasm and ejaculation . Urology. 
2016, 6:9-21. 10.1016/j.urology.2016.02.018

13. Holstege G, Georgiadis JR, Paans AM, Meiners LC, Van der Graaf FH, Reinders AA: Brain activation during human male ejaculation. J Neurosci. 2003, 8:9185-93. 10.1523/JNEUROSCI.23-27-09185.2003

14. Núñez R, Gross GH, Sachs BD: Origin and central projections of rat dorsal penile nerve: Possible direct projection to autonomic and somatic neurons by primary afferents of nonmuscle origin. J Comp Neurol. 1986, 247:417-29. 10.1002/cne.902470402

15. Comarr AE: Sexual function among patients with spinal cord injury . Urol Int. 1970, 6:134-68.

16. Gerstenberg TC, Levin RJ, Wagner G: Erection and ejaculation in man. Assessment of the electromyographic activity of the bulbocavernosus and ischiocavernosus muscles. Br J Urol. 1990, 65:395-402.

17. Blanker MH, Bosch JL, Groeneveld FP: Erectile and ejaculatory dysfunction in a community-based sample of men 50 to 78 years old: prevalence, concern, and relation to sexual activity. Urology. 2001, 57:763-8.

18. Nickel JC, Elhilali M, Vallancien G: Benign prostatic hyperplasia (BPH) and prostatitis: Prevalence of painful ejaculation in men with clinical BPH. BJU Int. 2005, 95:571-4. 10.1111/j.1464-410X.2005.05341.X

19. Litwin MS, McNaughton-Collins M, Fowler FJ: The National Institutes of Health chronic prostatitis symptom index: development and validation of a new outcome measure. J Urol. 1999, 162:369-75. 10.1016/S0022-5347(05)68562-X

20. Barnas JL, Pierpaoli S, Ladd P: The prevalence and nature of orgasmic dysfunction after radical prostatectomy. BJU Int. 2004, 94:603-5. 10.1111/j.1464-410X.2004.05009.x

21. Zaidi S, Gandhi J, Seyam O: Etiology, diagnosis, and management of seminal vesicle stones . Curr Urol. 2019, 8093:113-20. 10.1159/000489429

22. Sundar R, Sundar G: Zinner syndrome: an uncommon cause of painful ejaculation . BMJ Case Rep. 2015, 2015:1-5. 10.1136/bcr-2014-207618

23. Lira Neto FT, Bach PV, Miranda E de P: Management of ejaculatory duct obstruction by seminal vesiculoscopy: case report and literature review. JBRA Assist Reprod. 2020, 00:1-5. 10.5935/15180557.20190075

24. Kang PM, Seo WI, Yoon JH, Kim TS, Chung J: Transutricular seminal vesiculoscopy in the management of symptomatic midline cyst of the prostate. World J Urol. 2016, 34:985-92.

25. Wang H, Ye H, Xu C: Transurethral seminal vesiculoscopy using a $6 \mathrm{~F}$ vesiculoscope for ejaculatory duct obstruction: initial experience. J Androl. 201, 33:637-43. 10.2164/jandrol.111.013912

26. Robert R, Prat-Pradal D, Labat JJ: Anatomic basis of chronic perineal pain: role of the pudendal nerve . Surg Radiol Anat. 1998, 20:93-8. 10.1007/BF01628908

27. Shoskes DA, Landis JR, Wang Y, Nickel JC, Zeitlin SI, Nadler R: Impact of post-ejaculatory pain in men with category III chronic prostatitis/chronic pelvic pain syndrome. J Urol. 2004, 172:542-7. 10.1097/01.ju.0000132798.48067.23

28. Simpson GM, Blair JH, Amuso D: Effects of antidepressants on genito-urinary function . Dis Nerv Syst. 1965, 26:787-789.

29. Kraus MB, Wie CS, Gorlin AW, Wisenbaugh ES, Rosenfeld DM: Painful ejaculation with cyclobenzaprine: a case report and literature review. Sex Med. 2015, 3:343-5. 10.1002/sm2.93

30. Shapiro EI, Silber SJ: Open-ended vasectomy, sperm granuloma, and postvasectomy orchialgia . Fertil Steril. 1979, 32:546-50. 10.1016/S0015-0282(16)44357-8

31. Gray M, Zillioux J, Khourdaji I, Smith RP: Contemporary management of ejaculatory dysfunction. Transl Androl Urol. 2018, 7:686-702. 10.21037/tau.2018.06.20

32. Johnson CW, Bingham JB, Goluboff ET, Fisch H: Transurethral resection of the ejaculatory ducts for treating ejaculatory symptoms. BJU Int. 2005, 95:117-9. 10.1111/j.1464-410X.2004.05261.x

33. Barnas J, Parker M, Guhring P, Mulhall JP: The utility of tamsulosin in the management of orgasmassociated pain: a pilot analysis. Eur Urol. 2005, 47:361-5. 10.1016/j.eururo.2004.10.020

34. Jordi PM, Maria-José AM, Luis-Alfonso MM, Mauro SM: Management of ejaculation pain with topiramate: a case report. Clin J Pain. 2004, 20:368-369. 